\title{
Research on dynamic characteristics of gas film of spherical hybrid gas bearings based on computational fluid dynamics
}

\author{
Chenhui Jia ${ }^{1}$, Zhiwu Cui ${ }^{1 *}$, Shijun $\mathrm{Guo}^{2}$, Wensuo $\mathrm{Ma}^{3}$ \\ ${ }^{1}$ School of Mechatronics Engineering, Henan University of Science and Technology, Luoyang, \\ China; \\ ${ }^{2}$ Cranfield University, School of Aerospace, Transport and Manufacturing, England; \\ 3 Collaborative Innovation Center of Machinery Equipment Advanced Manufacturing of Henan \\ Province, China
}

Corresponding author's email: ccuizhiwu@163.com

\begin{abstract}
The Realizable k- $\varepsilon$ turbulence model for the spherical spiral groove hybrid gas bearings film was established based on computational fluid dynamics (CFD). The 6-degrees of freedom (DOF) passive grid was used to numerically calculate the gas film pressure distribution, the bearing capacity and the dynamic characteristic coefficients. The gas flow field dynamic and static pressure coupling mechanism was studied. The effect of rotation speed, gas film thickness eccentricity ratio and gas supply pressure on the dynamic and static pressure bearing capacity and the dynamic characteristic coefficients during operation were analyzed as a method of research into the mechanical mechanism of gas bearing stability. The CFD simulation calculation analysis can simulate the complex gas flow in the transient flow field of the gas film, and find the reasonable operation parameters to optimize dynamic and static pressure coupling effects, which can improve the gas film bearing capacity, dynamic characteristics and the operating stability of gas bearings.
\end{abstract}

Keywords: Gas bearing; 6-degrees of freedom passive grid; Gas film pressure distribution; Dynamic and static pressure coupling effects; Steady Bearing Performance; Dynamic characteristic coefficients 


\begin{tabular}{|c|c|}
\hline$b_{r}$ & table width \\
\hline$b_{g}$ & groove width \\
\hline $\bar{b}$ & groove width ratio \\
\hline$b_{i j}$ & damping coefficients \\
\hline $\operatorname{div}(\rho u)$ & divergence of velocity vector \\
\hline$h_{g}$ & groove area clearance \\
\hline$h_{0}$ & average gas film clearance \\
\hline $\bar{h}$ & groove depth ratio \\
\hline$k_{i j}$ & stiffness coefficients \\
\hline$S$ & the generalized source terms of the conservation of momentum equation \\
\hline$t$ & flow time \\
\hline$u 、 k \quad w$ & the velocity component of the velocity vector in the $\mathrm{x}, \mathrm{y}, \mathrm{z}$ directions \\
\hline$\Delta F_{x}, \Delta F_{\mathrm{y}}$ & variation of bearing gas film force \\
\hline$\Delta x, \Delta y$ & displacement change in $\mathrm{x}$ and $\mathrm{y}$ directions \\
\hline$\Delta v_{x} 、 \Delta \mathbf{v}_{y}$ & velocity change in $\mathrm{x}$ and $\mathrm{y}$ directions \\
\hline \multicolumn{2}{|c|}{ Greek symbols } \\
\hline$\alpha$ & wrap angle \\
\hline$\beta$ & helix angle \\
\hline$\varepsilon$ & dimensionless eccentricity ratio \\
\hline$\theta$ & gas supply hole angle \\
\hline$\phi_{1}$ & diameter of the bearing \\
\hline$\phi_{2}$ & diameter of the gas supply hole \\
\hline$\mu$ & dynamic viscosity \\
\hline$\rho$ & air density \\
\hline$\omega$ & rotation speed \\
\hline
\end{tabular}

\section{Introduction}

Spherical spiral groove hybrid gas bearings have orifices on the surface of the bearing and spiral grooves on the rotor. On the one hand, the static pressure effect is formed by introducing the external high pressure gas into the bearing clearance through the restrictor. On the other hand, the gas flows through the wedge-shaped gap to form the dynamic pressure effect. They are coupled to form the bearing performance of the bearings. At the same time the bearing has high rotation accuracy, compact structure, and it can provide three degrees of freedom of low friction high-speed 
movement (Ma et al. 2010; Zhang et al 2011; Lu et al. 2014).

Static and dynamic pressure lubrication can meet the needs of low speed, and can maintain stable working ability at high speed. The dynamic pressure effect is greatly influenced by rotation speed, the higher the speed, the large eccentricity ratio and the more obvious the dynamic pressure effect. In order to obtain large bearing capacity, the gas bearing needs to increase the structure of spiral groove, increase eccentricity ratio and reduce the average gas film thickness to enhance the dynamic pressure effect. However, when the rotation speed is high, the gas film force of the gas film whirl is increased, which results in the typical whirl instability (Wang et al. 2016; Rashidi et al. 2010). The change in the stability of the gas film is determined by the mechanical properties of the gas film during high-speed operation of gas bearings. The dynamic characteristic coefficients of the gas film reflect the variation law of the gas film force when the journal deviates from the static equilibrium position and the displacement movement in the vicinity, which has very complex nonlinear and stochastic characteristics. The random variation of the gas film dynamic characteristics will cause the change of the gas film motion state. It is expressed as a random change of the stability of the gas film, and directly affects the motion state of the bearing rotor (San Andrés 2006; Yu et al. 2015; Jia et al. 2016). Therefore, the calculation and analysis of dynamic characteristics of bearing gas film is the key to study the stability of gas bearing (Li 2017).

Hitherto, the majority of scholars have studied gas bearing stability by using basic experimental and theoretical investigations (Jia et al. 2017; Qi et al. 2007; Zhang et al. 2014). The theoretical calculation is basically based on the Reynolds lubrication equation. By using the Perturbation method, Difference method, Finite element method and other numerical methods, the linear equations are solved, and the dynamic characteristic coefficients are calculated to analyze the stability of the bearing. Because the Reynolds Equation can not accurately reflect the nonlinear coupling relation between the circumferential inertial effect of high speed airflow, the circumferential dynamic pressure effect of the journal and the static pressure diffusion effect, and the effect on the three-dimensional flow field characteristics. Therefore, the calculation of the stiffness and damping of the gas film deviates from the true value and the error is large. The real motion state of the bearing cannot be accurately analyzed (Zhang and Liu 2011; Liu and Wang 2011). However, testing the dynamic characteristic coefficients of the bearing ask for the rigorous experimental conditions. In the test process, various external factors inevitably interfere with the test, which makes the test result have certain error.

In this study, the Realizable k- $\varepsilon$ turbulence model of the spherical spiral groove hybrid gas bearings gas film was established based on FLUENT. The pressure distribution on the grid point of the gas film was numerically calculated by using 6DOF passive grid, thereby simulating the 
complex gas flow in the transient flow field of the gas film. The effect of gas film thickness, eccentricity ratio and gas supply pressure on the dynamic and static pressure bearing capacity and the dynamic characteristic coefficients during operation were analyzed. The dynamic and static pressure coupling effects of gas flow field was studied and the mechanical mechanism of gas bearing stability was studied, which can increase the bearing capacity of gas film, optimize the dynamic characteristics, reduce the gas film whirl, and provide a theoretical basis for improving the operating stability of gas bearing.

\section{Finite element model of gas bearing}

\subsection{Three - dimensional model of bearing gas film}

For researching the spherical spiral groove hybrid gas bearings, the bearing consists of two portions, namely the rotor and stator. A certain number of air holes exist on the stator, while the rotor contains spiral grooves in the groove and platform areas, as illustrated in Fig. 1. Following the introduction of external high-pressure gas by the restrictor to the bearing clearance, a hydrostatic gas film is formed, resulting in hydrostatic bearing capacity. Moreover, a wedging effect between the rotor and stator is produced when the bearing rotates at a high speed; a dynamic pressure gas film is formed, resulting in dynamic bearing capacity. The transient flow field characteristics of the gas film reflect the steady bearing performance, dynamic characteristic coefficients, and stability of the bearing during operation.

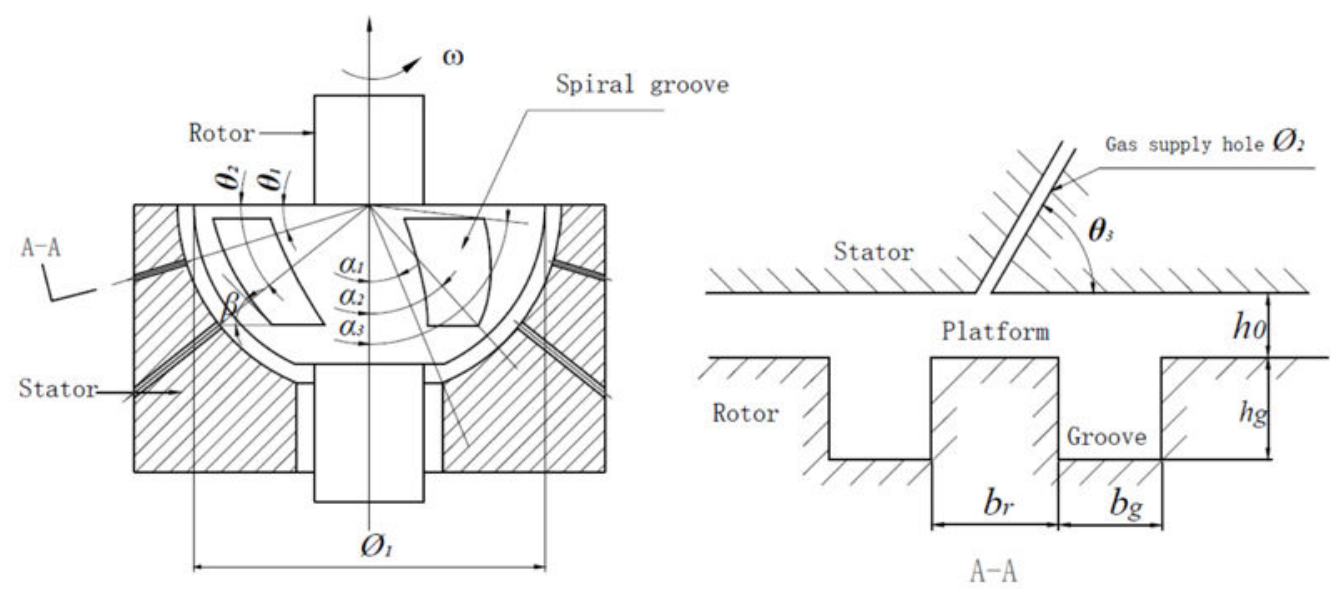

Fig. 1 Spherical spiral groove hybrid gas bearings profile diagram

In Fig $1, \beta$ is the helix angle, $\phi_{1}$ is the diameter of the bearing, $\phi_{2}$ is the diameter of the gas supply hole, $\omega$ is the rotation speed, $b_{r}$ is the table width, $b_{g}$ is the groove width, $h_{g}$ is the groove area clearance, $h_{0}$ is the average gas film clearance, groove depth ratio $\bar{h}=\left(h_{0}+h_{g}\right) / h_{0}$, groove width 
ratio $\bar{b}=b_{g} /\left(b_{r}+b_{g}\right), \theta$ for the gas supply hole angle, $\alpha_{1} 、 \alpha_{2} \alpha_{3}$ for the wrap angle, $\theta_{1} 、 \theta_{2}$ is the axial supply hole angle, $\theta_{3}$ is the tangential angle with reversely tangential gas supply holes.

Model structure parameters: $\phi_{1}=15 \mathrm{~mm}, \phi_{2}=0.2 \mathrm{~mm}, \beta=70^{\circ}, \mathrm{h}_{0}=10 \mu \mathrm{m}, \alpha_{1}=26^{\circ}, \alpha_{2}=32^{\circ}, \alpha_{3}=85^{\circ}$, dimensionless eccentricity ratio $\varepsilon=0.3$, groove width ratio $\bar{b}=0.4$, groove depth ratio $\bar{h}=3.6$. Using the space spherical coordinate system and the helix, the three-dimensional gas film model was established using Pro/E according to the structural parameters of the bearing. Change the default precision in Pro / E to $1 \mu \mathrm{m}$ to meet the high accuracy requirements of the model. The threedimensional model of the gas film is shown in Fig 2.
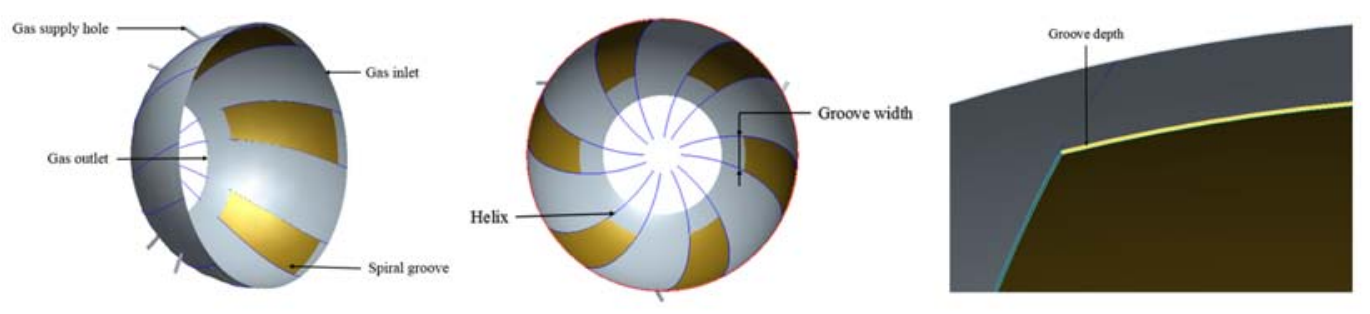

Fig. 2 Spherical spiral groove hybrid gas bearings gas film three-dimensional model

\subsection{Governing equation}

In this paper, the lubrication flow field in the gas bearing can be described by the mass conservation equation and the momentum conservation equation.

(1) Mass conservation equation

$$
\frac{\partial \rho}{\partial t}+\operatorname{div}(\rho u)=0
$$

Where $\rho$ is the air density; $t$ is the flow time; $\operatorname{div}(\rho u)$ is the divergence of the velocity vector $u$.

(2) The momentum conservation equation

$$
\begin{aligned}
& \frac{\partial(\rho u)}{\partial t}+\operatorname{div}(\rho u \bar{u})=\operatorname{div}(\mu \operatorname{grad} u)-\frac{\partial \rho}{\partial x}+S_{u} \\
& \frac{\partial(\rho v)}{\partial t}+\operatorname{div}(\rho v \bar{u})=\operatorname{div}(\mu \operatorname{grad} v)-\frac{\partial \rho}{\partial y}+S_{v} \\
& \frac{\partial(\rho w)}{\partial t}+\operatorname{div}(\rho w \bar{u})=\operatorname{div}(\mu \operatorname{grad} w)-\frac{\partial \rho}{\partial z}+S_{w}
\end{aligned}
$$


Where $\mu$ is the dynamic viscosity; $S_{u} 、 S_{v} S_{w}$ is the generalized source terms of the conservation of momentum equation; $u, k w$ is the velocity vector on the $\mathrm{x}, \mathrm{y}, \mathrm{z}$ direction of the velocity components.

\subsection{Finite element mesh model}

The gas bearing is meshed by FLUENT pretreatment software ICEM CFD. Due to the large difference in size of the spherical spiral groove hybrid gas bearings in the three directions of the space, the gas film thickness is generally within a few tens of microns. It is more reasonable to use structured grid partition method, which can improve the precision of numerical calculation and save calculation time, and reduce the probability of the negative volume of the grid. After comparing and analyzing the calculation results of the calculation model under different grid densities. It is found that the different grid numbers in the gas supply hole and the spiral groove lead to the difference of the calculation results. The grid was properly encrypted in the position of the gas supply hole and the spiral groove, O-type grids were used in the gas supply holes. The grid of the gas film is shown in Fig 3.
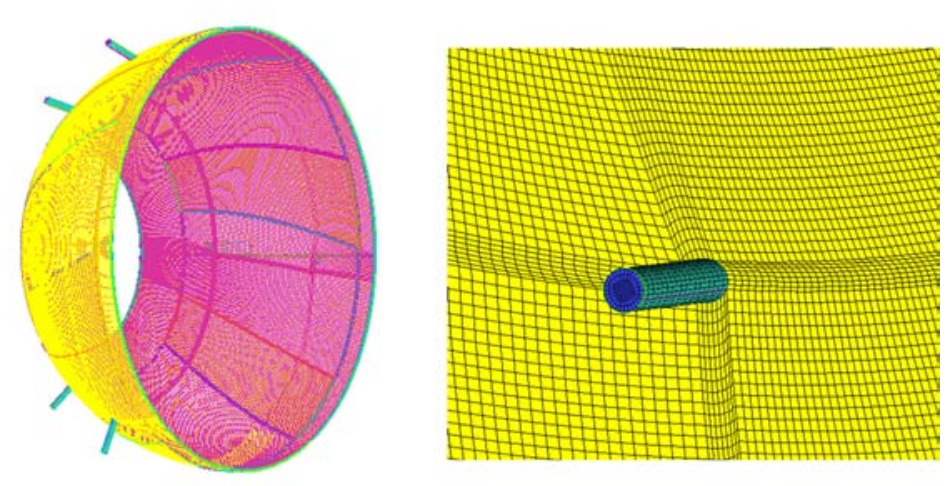

Fig. 3 Finite element calculation model

\section{Numerical calculation of flow field}

\subsection{FLUENT calculation model and model hypothesis}

\subsubsection{The flow Realizable $k-\varepsilon$ model}

In the dynamic calculation of the model, FLUENT mainly has active and passive grid two ways to control the model of the grid deformation. The active dynamic grid is usually used in the boundary motion law and the motion state is known. The boundary motion trajectory program is 
called to simulate the boundary motion, and the transient flow field characteristics of the model are calculated. The passive dynamic grid is usually used for the boundary motion and the motion state is unknown. It is often necessary to obtain the boundary motion by calculating the force or torque on the boundary. The spherical spiral groove hybrid gas bearings motion state is unknown, it is mainly by the bearing structure parameters, rotation speed, gas supply pressure, external load and other factors. Therefore, the passive grid is more appropriate to calculate the dynamic characteristics of the bearing, and it can also simulate the motion characteristics of the bearing gas film more realistically.

The k- $\varepsilon$ model of the turbulence model is a two-equation model, which contains the transport equation for the turbulent kinetic energy $\mathrm{k}$ and the equation for the turbulent dissipation rate $\varepsilon$. The $\mathrm{k}-\varepsilon$ model is also divided into standard k- $\varepsilon$ model, RNG k- $\varepsilon$ model, and Realizable k- $\varepsilon$ model. The Realizable k- $\varepsilon$ model is applied to the flow of higher mainstream shear rate and larger curvature. It can achieve better calculation results for the swirling flow, boundary layer flow with strong pressure gradient and complex secondary flow. Spherical spiral groove hybrid gas bearings with a smaller size, the speed can be up to tens of thousands or even hundreds of thousands during the operation. When the bearing rotates at high speed, the motion of the gas film will appear as whirl and cyclone. This model can well simulate the cyclone phenomenon at the gas supply hole. So the Realizable $\mathrm{k}-\varepsilon$ turbulence model is adopted in this paper.

\subsubsection{Model hypothesis}

The lubrication analysis model of the spherical helical groove hybrid gas bearings reflects the pressure field and velocity field distribution, dynamic bearing characteristics, and lubrication characteristics of the gas film in the bearing clearance. In the calculation of the fluid has the following assumptions: (1) The lubricating medium is Newton fluid, and the gas viscosity coefficient is constant; (2) There is no heat exchange between the gas and the wall, and the thermal deformation of the bearing and journal is not is not considered during the rotation; (3) In the direction perpendicular to the thickness of the gas film, the velocity change is neglected, that is the pressure does not change along the gas film thickness; (4) The gas does not have relative sliding on the shaft and bearing surfaces; (5) The wall is assumed to be smooth, without considering the influence of wall roughness and slip boundary.

\subsubsection{Boundary conditions}

The flow field calculations use three boundary conditions for the inlet, outlet, and wall. (1) 
The gas supply hole of the gas bearing is the pressure inlet boundary condition, and the total inlet pressure is provided in the calculation. (2) The large end of the gas bearing is the pressure inlet boundary condition, and the pressure is set as ambient atmospheric pressure, according to the actual situation. (3) The small end of the gas bearing is also a pressure boundary condition, and the pressure is set as ambient atmospheric pressure, according to the actual situation. (4) The remaining boundary of the bearing is set as a wall surface, and no relative sliding occurs between the wall surfaces. The inner wall surface of the gas film is set as a rotating rigid wall, while the outer wall surface of the gas film and wall surface of the gas supply hole are set as fixed wall surfaces.

\subsection{Steady-state solution calculation}

After introducing the gas bearing grid into FLUENT, the 3D pressure base implicit solver is selected, and the boundary conditions of the flow field calculation are set up. PISO algorithm is used in the pressure and velocity coupling, and the algorithm is based on SIMPLE algorithm. The difference between the two is that after a given pressure to solve the momentum equation and the continuous equation, the PISO algorithm needs to correct the pressure and velocity equations twice, so that the pressure and velocity reach the second and third order precision of the moment. Due to the influence of the high speed rotation of the journal on the flow field, the interpolation discrete format of the pressure equation chooses PRESTO. The residual difference of all equations is less than 0.0001, and the flow rate of the inlet and outlet is monitored during the calculation. And the calculation is convergent when the numerical value is basically equal.

The steady-state calculation is based on the given structural parameters and operating parameters. It is assumed that the gas bearing can operate stably under given radial and axial eccentric conditions, and through the FLUENT simulates the flow field in the gas film clearance. The pressure field and velocity field distribution at each grid point of gas film are calculated numerically, and the steady gas film pressure distribution and the steady state bearing performance are obtained. The steady-state calculation flow chart as shown in Fig 4: 


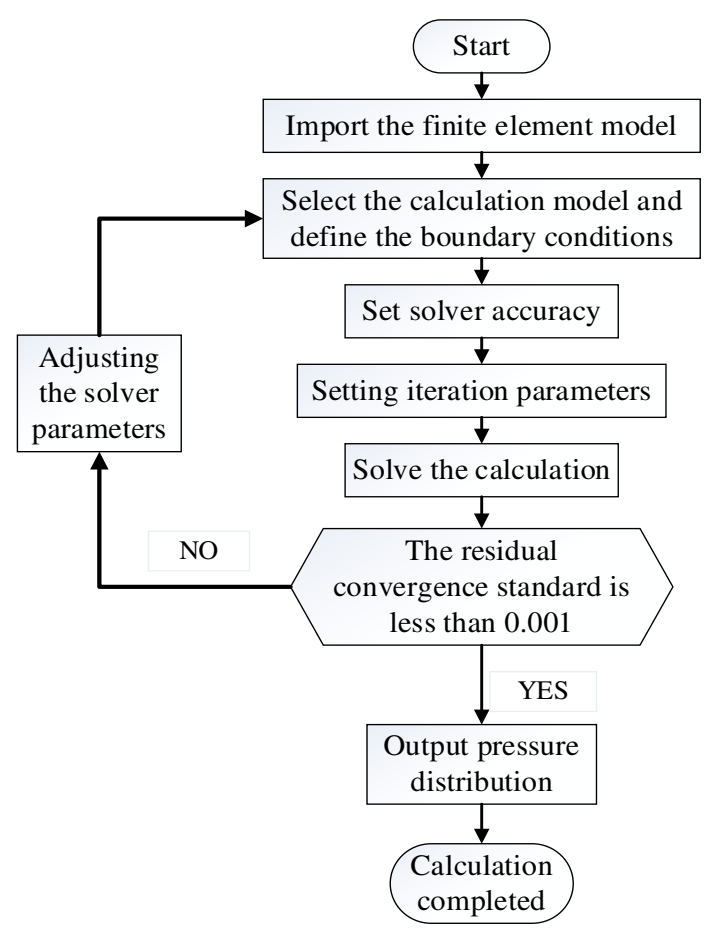

Fig. 4 Steady-state simulation calculation flow chart

\subsection{Calculation of dynamic characteristic coefficients}

The gas bearing is based on the given structural parameters and operating parameters, and through the FLUENT simulates the flow field in the gas film clearance. The pressure distributions at each grid point of gas film are calculated numerically, and the dynamic characteristic coefficients of the bearing is obtained. The dynamic calculation flow chart as shown in Fig 5: 


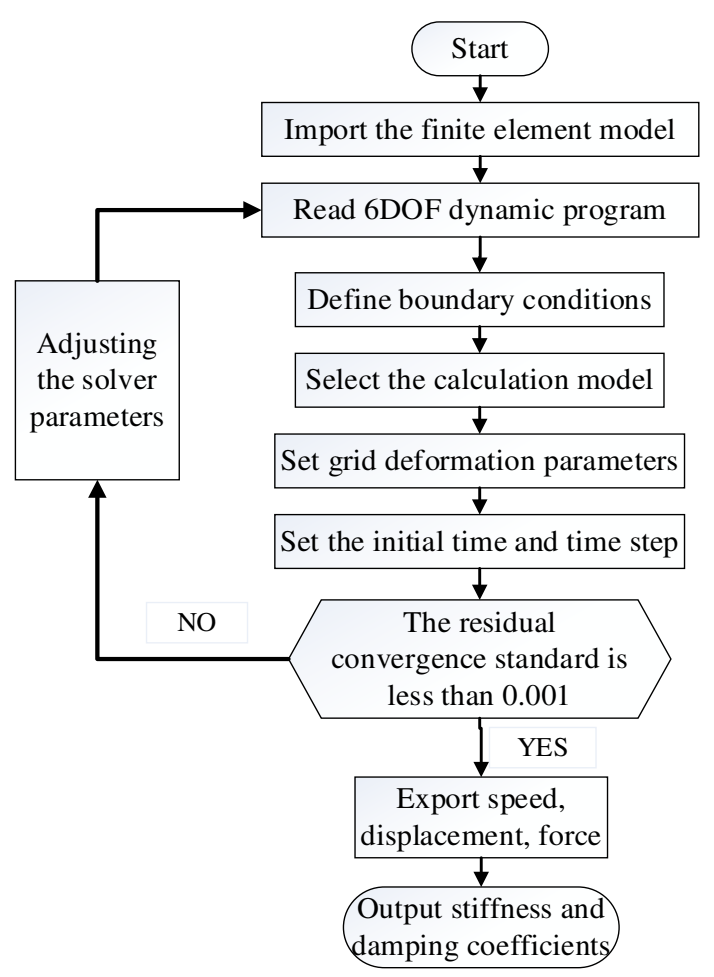

Fig. 5 Dynamic simulation calculation flow chart

In dynamic calculations, select a period of time during the simulation and output the force, velocity, and displacement of the gas film at each time step. First select a group of data, then use the rest of the data to calculate the dynamic stiffness damping coefficient according to the following formula. Observe the data distribution and remove the distorted data. Finally, obtain the average value to obtain the dynamic stiffness damping coefficient of the bearing.

$$
\left\{\begin{array}{l}
\Delta F_{x}=k_{x x} \cdot \Delta x \\
\Delta F_{x}=k_{x y} \cdot \Delta y \\
\Delta F_{y}=k_{y y} \cdot \Delta y \\
\Delta F_{y}=k_{y x} \cdot \Delta x
\end{array},\left\{\begin{array}{l}
\Delta F_{x}=b_{x x} \cdot \Delta v_{x} \\
\Delta F_{x}=b_{x y} \cdot \Delta v_{y} \\
\Delta F_{y}=b_{y y} \cdot \Delta v_{y} \\
\Delta F_{y}=b_{y x} \cdot \Delta v_{x}
\end{array}\right.\right.
$$

Where $\Delta F_{x} 、 \Delta F_{\mathrm{y}}$ is the variation of the gas film force of the bearing, $k_{x x} 、 k_{y y}$ is the direct stiffness coefficients, $k_{x y} 、 k_{y x}$ is the cross stiffness coefficients, $b_{x x}, b_{y y}$ is the direct damping coefficients, $b_{x y}, b_{y x}$ is the cross damping coefficients, $\Delta x, \Delta y$ are displacement variations of bearings in the $\mathrm{X}$ and $\mathrm{Y}$ directions respectively, $\Delta v_{x} 、 \Delta \mathrm{v}_{y}$ are the velocity variations of the bearing in $\mathrm{X}$ and $\mathrm{Y}$ direction respectively. 


\section{The dynamic and static pressure coupling effect on bearing capacity}

\subsection{Bearing gas film pressure distribution and the dynamic-static pressure coupling effect}

The gas film pressure distribution of the spherical spiral groove hybrid gas bearings is mainly influenced by the operation parameters and the structural parameters of the bearings. The influence of the coupling between static pressure and dynamic pressure on the steady bearing performance of bearing is studied through the analysis of the pressure distribution characteristics of the bearing gas film (Miyatake and Yoshimoto 2010; Nishio et al. 2011; Yu et al. 2009).

Bearing structure parameters: dimensionless eccentricity ratio $\varepsilon=0.3$, helix angle $\beta=70^{\circ}$, groove width ratio $\bar{b}=0.4$, groove depth ratio $\bar{h}=3.6$, the number of grooves is 6 , tangential angle $\theta_{3}=55^{\circ}$.

\subsubsection{The static pressure effect dominates for high gas supply pressures}

The bearing operating parameters of the bearing are set to gas supply pressure of $0.6 \mathrm{MPa}$ and rotation speed of $30000 \mathrm{r} / \mathrm{min}$. Fig $6 \mathrm{a}$ presents a pressure nephogram with a rotation speed of $30000 \mathrm{r} / \mathrm{min}$ and a gas film thickness of $10 \mu \mathrm{m}$, while Fig $6 \mathrm{~b}$ is a circumferential pressure distribution diagram at the gas supply holes when the average film thickness is $5 \mu \mathrm{m}, 10 \mu \mathrm{m}$ and $20 \mu \mathrm{m}$. Fig 6 shows that the gas film pressure is primarily generated by an external gas supply. The gas film pressure is significantly greater near the gas supply holes, and a certain wedge effect is present as the gas flows, which produces a weak dynamic pressure effect. The resulting dynamic pressure enhancement was not significant at the intersection of groove and stage. However, the reduction in gas film thickness is conducive to the generation of the dynamic pressure effect. The bearing capacity and dynamic characteristics of the gas film primarily depend on the static pressure effect. 


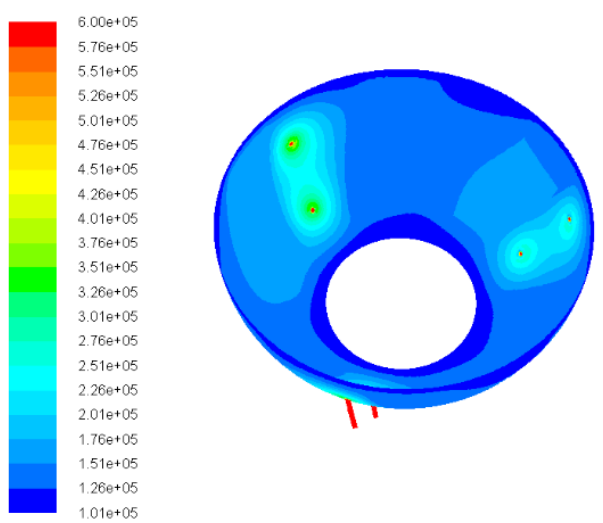

a. Gas film pressure nephogram

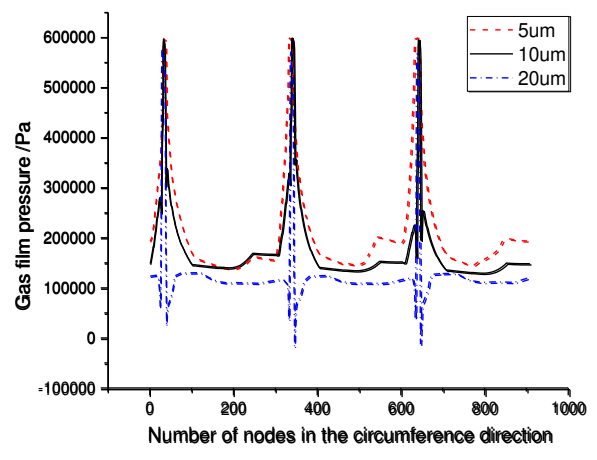

b. Gas film circumferential pressure distribution

Fig. 6 Gas film pressure nephogram and circumferential pressure distribution of different gas film thicknesses

\subsubsection{The dynamic pressure effect dominates for low gas supply pressures}

The average film thickness $10 \mu \mathrm{m}$, the bearing gas supply pressure is $0.1 \mathrm{MPa}$. Fig 7a presents a pressure nephogram with a rotation speed of $30000 \mathrm{r} / \mathrm{min}$ and a supply pressure of $0.11 \mathrm{MPa}$, and Fig $7 \mathrm{~b}$ provides a circumferential pressure distribution diagram at the gas supply holes when the rotation speed is 10000r/min 、30000r/min and 60000r/min. Fig 7 indicates that, if the gas supply pressure is very low, the generation of the gas film bearing capacity mainly depends on the dynamic pressure effect. The gas flow presents a wedge effect. The gas film pressure distribution shows a convergence and divergence zone. The gas film pressure gradually increases in the convergence zone, approaching the region with the smallest gas film thickness, where the gas pressure is largest. The gas film pressure rapidly decreases in the divergence zone, where negative pressure appears in some regions; the gas film also shows an abrupt change at the intersection of groove and stage of the bearing spiral groove. On one side of the groove junction, the gas film pressure increases steeply but declines suddenly on the other side. The higher the rotation speed, the more significant the dynamic pressure effect. This indicates that the spiral groove effectively enhances the dynamic pressure effect. 


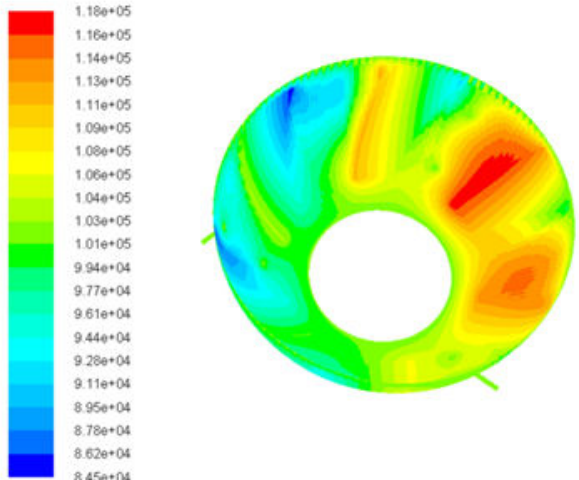

a. Gas film pressure nephogram

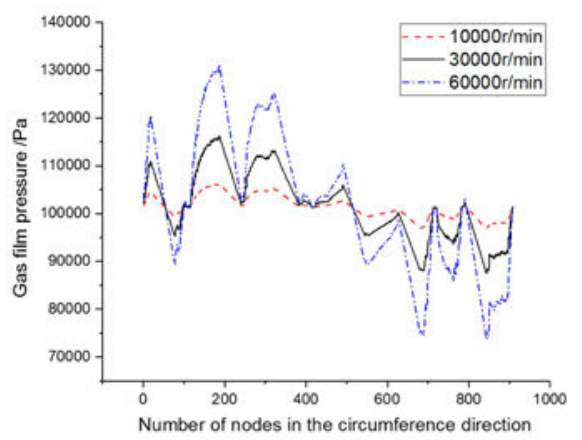

b. Gas film circumferential pressure distribution

Fig. 7 Gas film pressure nephogram and circumferential pressure distribution at gas supply pressure of $0.11 \mathrm{MPa}$

\subsubsection{The dynamic-static pressure coupling effect}

The average film thickness $10 \mu \mathrm{m}$, the bearing gas supply pressure is $0.3 \mathrm{MPa}$. Fig $8 \mathrm{a}$ presents a pressure nephogram with a rotation speed of 30000r/min and a supply pressure of $0.3 \mathrm{MPa}$, and Fig $8 \mathrm{~b}$ provides a circumferential pressure distribution diagram at the gas supply holes when the rotation speed is 10000r/min, 30000r/min, 60000r/min and 90000r/min. Fig 8 indicates that the static pressure effect increases significantly near the bearing's gas supply holes, while the dynamic pressure enhancement effect appears at the spiral groove. In addition, the gas film pressure increases with rotation speed, forming the dynamic-static pressure coupling effect that enables the gas film bearing capacity, which allows a more uniform pressure distribution in the circumferential direction and a better overall load distribution. The dynamic pressure effect is influenced by rotation speed; the higher the rotation speed, the larger the eccentricity ratio, and the more significant the dynamic pressure effect. A dynamic-static pressure bearing can maintain a reasonable dynamic pressure effect and simultaneously enhance the static pressure effect by increasing the gas supply pressure to improve the bearing load capacity and ensure improved stability for high loads. When the rotation speed is high, the bearing capacity is generated by the static pressure, and its extent of increase weakens as the gas supply pressure increases. However, the dynamic-static pressure coupling bearing capacity becomes larger at this point because of the larger dynamic pressure effect, since its magnitude is enhanced under high rotation speeds. Therefore, the coupling of dynamic and static pressures can complement one another not only by increasing the film bearing capacity but also by optimizing the dynamic characteristics and improving high-speed operation stability. 

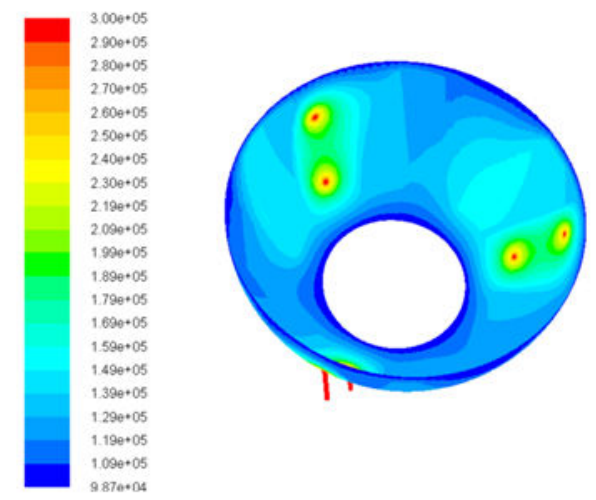

a. Gas film pressure nephogram with speed of $30000 \mathrm{r} / \mathrm{min}$

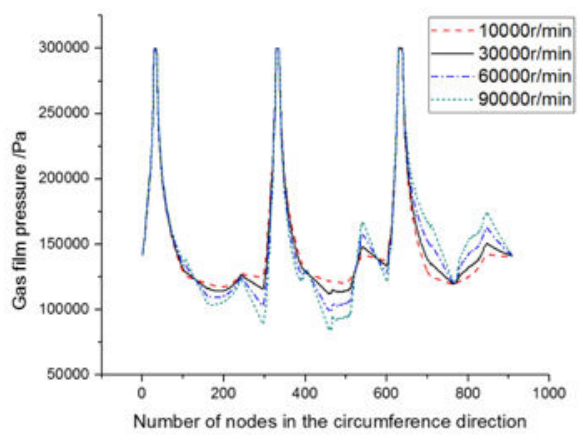

b. Gas film circumferential pressure distribution

Fig. 8 Gas film pressure nephogram and circumferential pressure distribution at gas supply pressure of $0.3 \mathrm{MPa}$

\subsection{Variation of operating parameters on the steady-state bearing capacity}

\subsubsection{Variation of gas film thickness on bearing capacity}

Fig 9 presents a regular diagram of bearing capacity changing with the rotation speed and the gas film thickness. Fig 9 demonstrates that the bearing capacity varies with film thickness for different rotation speeds in a consistent pattern. The bearing capacity decreases rapidly with increasing film thickness, and its rate of decline tends to slow as the film thickness exceeds $10 \mu \mathrm{m}$. The bearing capacity depends primarily on the static pressure effect generated by the gas supply pressure. Therefore, a film thickness of no more than $10 \mu \mathrm{m}$ should be selected to ensure high bearing capacity. In addition, the bearing capacity increases with rotation speed, and the dynamic pressure effect of bearings gradually becomes stronger, resulting in the enhancement of the dynamic-static pressure coupling effect that improves the bearing capacity of the gas film and its anti-disturbance capacity.

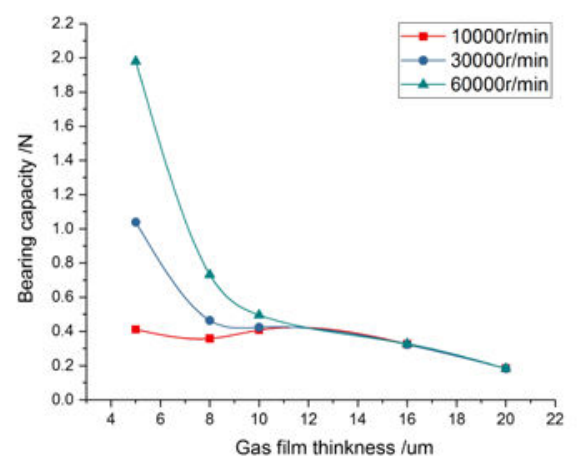


Fig. 9 Variation of gas film thickness on bearing capacity

\subsubsection{Variation of eccentricity ratio on bearing capacity}

Fig 10 presents a regular diagram of bearing capacity changing with the speed and the eccentricity ratio. Fig 10 reveals that the pattern of bearing capacity variation with eccentricity ratio for different rotation speeds is basically consistent. As eccentricity ratio gradually increases, the bearing capacity continuously increases. When the eccentricity ratio is less than 0.3 , the increase is linear but the rate is slow, and the effect of rotation speed on bearing capacity is weak. When the eccentricity ratio exceeds 0.3 , the bearing capacity increases rapidly. The higher the rotation speed results the greater the magnitude of the bearing capacity enhancement. The greater the eccentricity ratio, the more significant the dynamic pressure effect, the better the bearing and anti-disturbance capacities. However, increasing eccentricity ratio, reducing the minimum film thickness and increasing the axis whirl will not only make bearing design more complicated and provide challenges in manufacturing accuracy but also increase the potential for rub impact during operation, resulting in premature bearing failure. Therefore, proper selection of eccentricity ratio can enhance the dynamic pressure effect, improve bearing capacity and promote bearing stability.

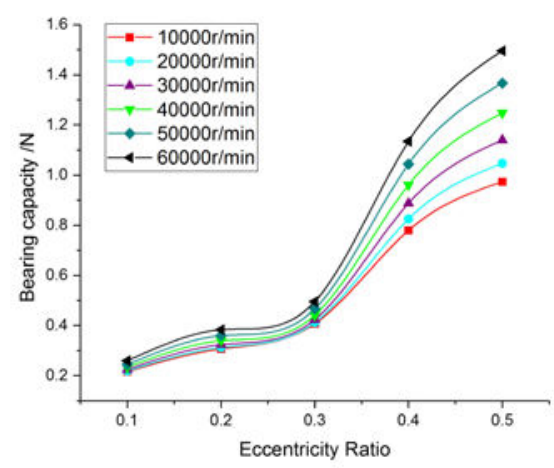

Fig. 10 Variation of eccentricity ratio on bearing capacity

\subsubsection{Variation of gas supply pressure on bearing capacity}

Fig 11 presents a regular diagram of bearing capacity changing with the rotation speed and the gas supply pressure. Fig 11 indicates that the pattern of bearing capacity variation with gas supply pressure for different rotation speeds is basically consistent. As gas supply pressure gradually increases, the bearing capacity continuously increases. When the gas supply pressure is less than $0.3 \mathrm{MPa}$, the bearing capacity increases at a slow rate. In this case, the dynamic pressure 
effect generated by the increase in rotation speed is becoming more significant, and the bearing capacity produced by the dynamic-static pressure coupling will be improved. When the gas supply pressure is greater than $0.3 \mathrm{MPa}$, the bearing capacity increases rapidly in a linear fashion, and it is less affected by the dynamic pressure effect produced by increasing rotation speed due to the dominance of the static pressure effect.

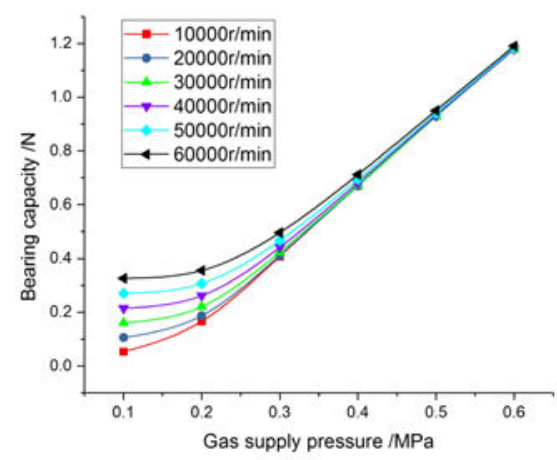

Fig. 11 Variation of gas supply pressure on bearing capacity

\section{Dynamic characteristics analysis}

When the hybrid gas bearings is running at high speed, the change of the speed, eccentricity ratio and gas supply pressure will cause the change of the flow field inside the gas film, and the characteristics of the gas film will be reconstructed. It will cause the change of the gas film thickness, the pressure distribution of the gas film, the nonlinear gas film force, the bearing performance, the dynamic characteristic coefficients and the stability (Chen et al. 2010; Xu et al. 2014; Theisen et al. 2015).

\subsection{Variation of rotation speed on dynamic characteristic coefficients}

The bearing gas supply pressure is $0.3 \mathrm{MPa}$.

Bearing structure parameters: dimensionless eccentricity ratio $\varepsilon=0.3$, the average gas film thickness $10 \mu \mathrm{m}$, helix angle $\beta=70^{\circ}$, groove width ratio $\bar{b}=0.4$, groove depth ratio $\bar{h}=3.6$, the number of grooves is 6 , tangential angle $\theta_{3}=55^{\circ}$. 


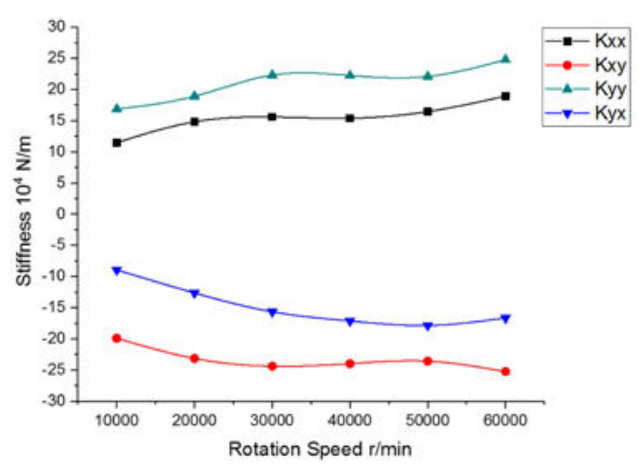

a.

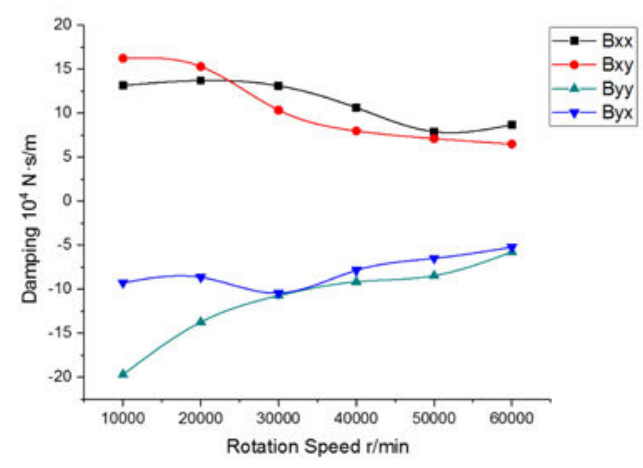

b.

Fig. 12 Variation of rotation speed on stiffness and damping coefficients

Fig 12a illustrates that, when the rotation speed is less than $30000 \mathrm{r} / \mathrm{min}$, the stiffness coefficient increases with increasing rotation speed. The direct stiffness coefficient $\mathrm{K}_{\mathrm{yy}}$ is greater than $\mathrm{K}_{\mathrm{xx}}$, and the cross stiffness $\mathrm{K}_{\mathrm{xy}}$ is greater than $\mathrm{K}_{\mathrm{yx}}$. With rotation speeds of 30000-50000r/min, $\mathrm{K}_{\mathrm{yy}}$ and $\mathrm{K}_{\mathrm{xy}}$ gradually decrease, while $\mathrm{K}_{\mathrm{xx}}$ and $\mathrm{K}_{\mathrm{yx}}$ slowly increase. When rotation speed is greater than 50000r/min, $\mathrm{K}_{\mathrm{xx}}, \mathrm{K}_{\mathrm{yy}}$, and $\mathrm{K}_{\mathrm{xy}}$ gradually increase, and $\mathrm{K}_{\mathrm{yx}}$ slowly decreases.

Fig $12 \mathrm{~b}$ indicates that, that when the rotation speed is lower than $30000 \mathrm{r} / \mathrm{min}$, the damping coefficients $B_{x x}$ and $B_{y x}$ gradually increase as the rotation speed increases. $B_{x y}$ and $B_{y y}$ slowly decrease as rotation speed increases. When the rotation speed is greater than $30000 \mathrm{r} / \mathrm{min}$, the stiffness damping coefficient declines rapidly as the rotation speed increases. When the rotation speed exceeds 40000r/min, the rate of decline in the damping coefficient tends to slow.

As the rotation speed increases, the dynamic pressure effect of the gas film is enhanced, the stiffness coefficient becomes larger, the bearing capacity increases, and the gas film antidisturbance capacity is strengthened. Integrating with the gas film stability state change process, when the rotation speed reaches $30000 \mathrm{r} / \mathrm{min}$, due to the mutual effects among cross-stiffness and cross-damping coefficients related to the trajectory shape and amplitude, the gas film begins to show instability that changes from linear to non-linear, resulting in a half-speed whirl of axis movement trajectory. As the rotation speed continues to increase, the stiffness coefficient gradually becomes larger, and the damping coefficient declines rapidly, causing the gas film whirl force to slowly become greater than the damping force. The axis movement trajectory will diverge further and become more chaotic, and the gas film stability worsens. Above 50000 $/ \mathrm{min}$, the axis movement trajectory will enter a chaotic state and appear rub impact, resulting in bearing failure. 


\subsection{Variation of gas supply pressure on dynamic characteristic coefficients}

The rotation speed of the bearing is $40000 \mathrm{r} / \mathrm{min}$.

Bearing structure parameters: dimensionless eccentricity ratio $\varepsilon=0.3$, the average gas film thickness $10 \mu \mathrm{m}$, helix angle $\beta=70^{\circ}$, groove width ratio $\bar{b}=0.4$, groove depth ratio $\bar{h}=3.6$, the number of grooves is 6 , tangential angle $\theta_{3}=55^{\circ}$.
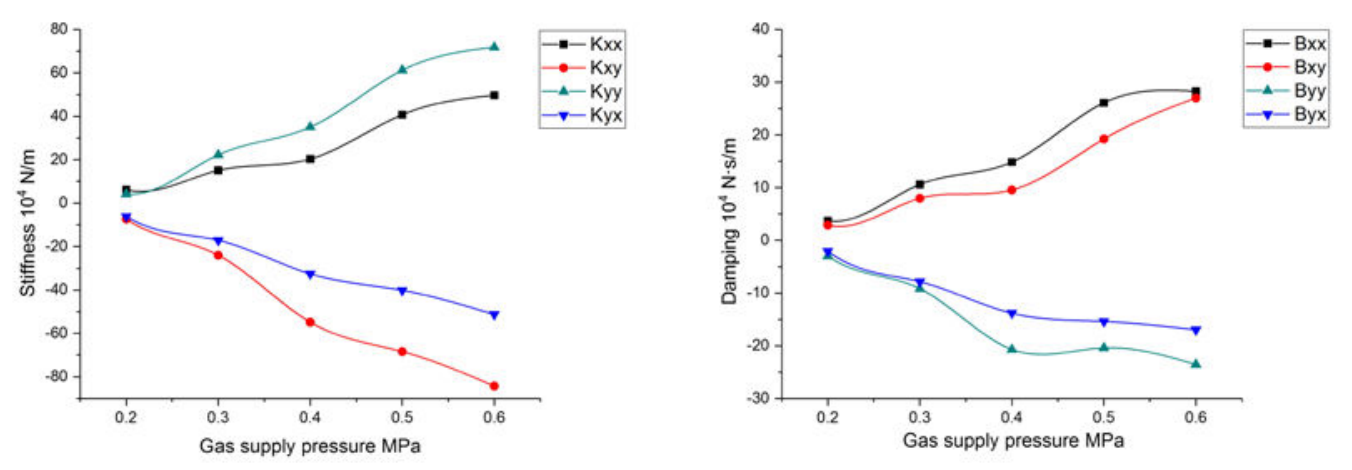

Fig. 13 Variation of gas supply pressure on stiffness and damping coefficients

Fig 13 illustrates that the direct stiffness coefficients $\mathrm{K}_{\mathrm{xx}}$ and $\mathrm{K}_{\mathrm{yy}}$ become larger as the gas supply pressure increases. The direct stiffness coefficient $\mathrm{K}_{\mathrm{yy}}$ and the cross-stiffness coefficient $\mathrm{K}_{\mathrm{xy}}$ tend to increase more rapidly. When the gas supply pressure exceeds $0.5 \mathrm{MPa}$, the rate of increase in the direct stiffness coefficient tends to gradually slow. The direct damping coefficients $B_{x x}$ and $B_{y y}$ tend to increase continuously in the opposite direction. The cross damping coefficients $\mathrm{B}_{\mathrm{xy}}$ and $\mathrm{B}_{\mathrm{yx}}$ increase constantly, but the tendency of increase is slow and in the opposite direction.

As the gas supply pressure increases, the stiffness and damping coefficients continue to increase, the bearing capacity and the dynamic stiffness coefficient are strengthened, and the antidisturbance and stability restoration capacity of the gas film are enhanced. However, the larger gas supply pressure will also cause the formation of gas film oscillation, which is easily coupled with the natural vibration of the system to generate resonance and cause self-excited vibration. As a result, the vibration amplitude of the axial movement increases, so the axis and the bearing are likely to collide with each other, resulting in bearing failure. When the gas supply pressure exceeds $0.5 \mathrm{MPa}$, the rate of increase in the stiffness coefficient tends to gradually slow. Therefore, the ability to improve the stiffness and stability of the gas film is weakened. For this reason, the selection of gas supply pressure should be kept in the range of $0.5 \sim 0.6 \mathrm{Mpa}$, which ensures a larger bearing capacity and gas film stiffness while allowing better operating stability. 


\subsection{Variation of eccentricity ratio on dynamic characteristic coefficients}

The operating parameters of the bearing are set to gas supply pressure of $0.3 \mathrm{MPa}$ and rotation speed of $40000 \mathrm{r} / \mathrm{min}$.

Bearing structure parameters: the average gas film thickness $10 \mu \mathrm{m}$, helix angle $\beta=70^{\circ}$, groove width ratio $\bar{b}=0.4$, groove depth ratio $\bar{h}=3.6$, the number of grooves is 6 , tangential angle $\theta_{3}=55^{\circ}$.
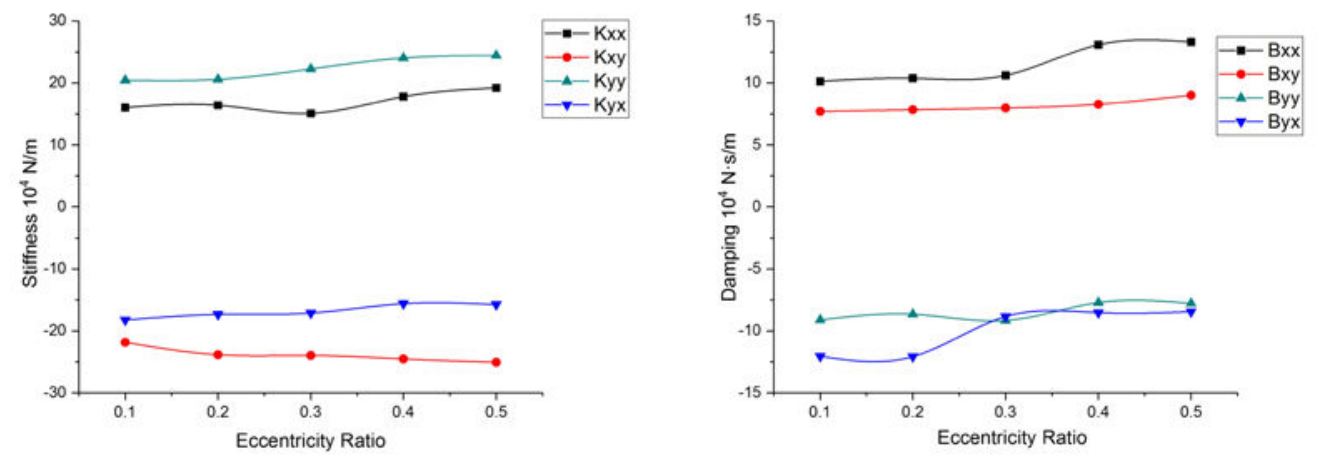

Fig. 14 Variation of eccentricity ratio on stiffness and damping coefficients

Fig 14 indicates that the direct stiffness coefficients $\mathrm{K}_{\mathrm{xx}}$ and $\mathrm{K}_{\mathrm{yy}}$ become larger as the eccentricity ratio increases, and the stiffness $\mathrm{K}_{\mathrm{yy}}$ in the bearing direction is greater than the stiffness coefficient $\mathrm{K}_{\mathrm{xx}}$ in the non-bearing direction. The cross stiffness coefficients $\mathrm{K}_{\mathrm{xy}}$ and $\mathrm{K}_{\mathrm{yx}}$ are less affected by the eccentricity ratio and the change trend is smaller. The damping coefficients $\mathrm{B}_{\mathrm{yy}}$ and $\mathrm{B}_{\mathrm{xy}}$ are less affected by the eccentricity ratio and the change trend is smaller. The direct damping coefficient $\mathrm{B}_{\mathrm{xx}}$ increases with the increase of eccentricity ratio, and the direct damping coefficient tends to increased significantly when the eccentricity ratio exceeds 0.3 . The cross damping coefficient $\mathrm{B}_{\mathrm{yx}}$ decreases with the increase of eccentricity ratio, and the damping coefficient tends to decreased significantly when the eccentricity ratio between 0.2 0.3.

A greater the eccentricity ratio, the stronger the dynamic pressure effect, the better the bearing capacity of the gas film, and the increase of the direct stiffness and damping coefficient of the bearing film. The damping of the gas film plays a role in the whirl energy consumption, which is a factor to restrain the whirl motion. The damping coefficient characterizes the rate of force variance with velocity. As the eccentricity ratio increases continuously, the dynamic pressure effect of the gas film is strengthened. As a result, the rotor must exert more work to overcome the gas film force. The direct damping coefficient tends to increase continuously; therefore, the suppression of the whirl effect becomes stronger, and the operation of the bearing rotor system becomes more 
stable. To allow greater stiffness and damping of a bearing gas film, along with higher bearing capacity, the selection of eccentricity ratio should be kept between 0.4-0.5.

\subsection{Variation of gas film thickness on dynamic characteristic coefficients}

The bearing operating parameters of the bearing are set to gas supply pressure of $0.3 \mathrm{MPa}$ and rotation speed of $40000 \mathrm{r} / \mathrm{min}$.

Bearing structure parameters: dimensionless eccentricity ratio $\varepsilon=0.3$, helix angle $\beta=70^{\circ}$, groove width ratio $\bar{b}=0.4$, groove depth ratio $\bar{h}=3.6$, the number of grooves is 6 , tangential angle $\theta_{3}=55^{\circ}$.
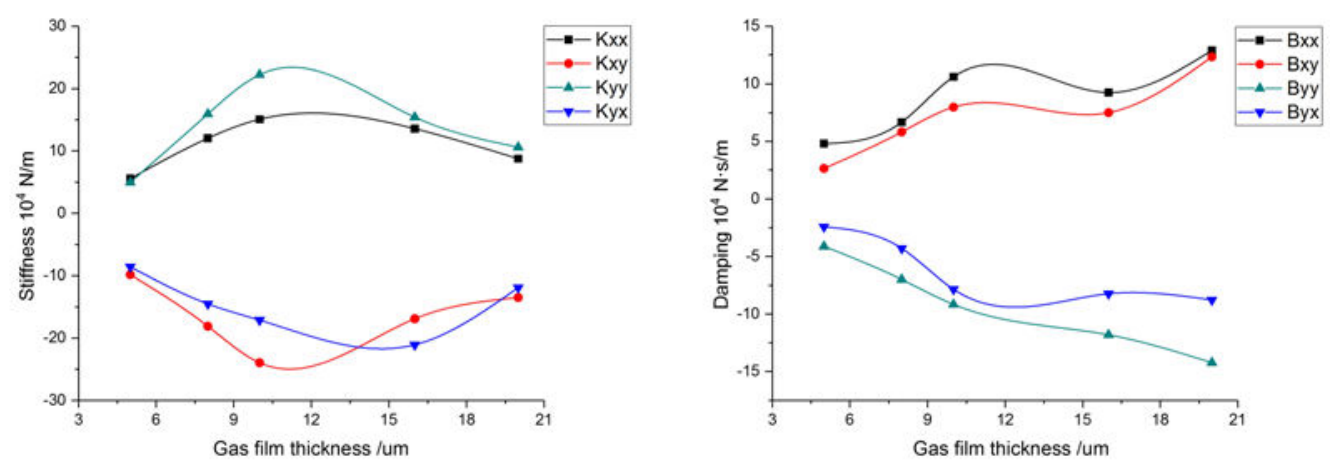

Fig. 15 Variation of gas film thickness on stiffness and damping coefficients

Figure 15 illustrates the relationship between the bearing gas film thickness and the stiffness and damping coefficients. The bearing stiffness coefficient first increases and then decreases with an increase in the gas film thickness. The direct stiffness coefficients Kxx and Kyy change more obviously, while the cross-stiffness coefficients Kxy and Kyx change slowly, and the maximum values of the direct stiffness coefficient of the bearings are obtained at a gas film thickness of approximately $10 \mu \mathrm{m}$. As the film thickness continues to increase, the bearing damping coefficient first increases and then decreases. The direct damping coefficients Bxx and Byy change more obviously, while the cross-damping coefficients Bxy and Byx change slowly.

The dynamic pressure effect is gradually weakened and the bearing capacity decreases with an increase in the gas film thickness. Overall, the bearing stiffness coefficient decreases with an increase in the gas film thickness. The increase of bearing stiffness coefficient is due to the influence of orifice-compensated modes. Because of the orifice effect and a decreased dispersion loss of the supply holes, the orifice-compensated modes increase the bearing stiffness at the optimum bearing gas film thickness. The gas film damping promotes a consumption effect on the whirl energy. Greater damping results in a stronger effect of suppressing the whirl and superior 
stability of the gas film. As the thickness of the gas film increases, the stability of bearings becomes worse and the film damping decreases. To allow for greater stiffness and damping of the gas film, and a higher bearing capacity, the selection of the gas film thickness should be maintained between 8 and $12 \mu \mathrm{m}$.

\section{Test verification}

\subsection{Test principles}

This experimental test system includes high pressure gas source I, bearing test machine II, signal detection system III, data processing system IV, the overall scheme as shown in Fig 16. The equipment 1-6 connected to form a high-pressure gas source I that provides the gas supply pressure of $0.8 \mathrm{MPa}$ and the gas supply flow rate of $2.4 \mathrm{~L} / \mathrm{min}$. The high-pressure gas source I provide highpressure gas to the bearing testing machine II, a part of which is used as a supporting gas to supply the gas bearing, and the other part is used as a power gas supplying turbine to drive the bearing rotor to rotation. The signal detection system III measures the gas film force, vibration displacement, vibration speed, and rotation speed of the gas bearing in the $\mathrm{X}, \mathrm{Y}$, and $\mathrm{Z}$ directions. The data processing system IV processes and calculates test data to obtain the gas film stiffness and damping coefficients.

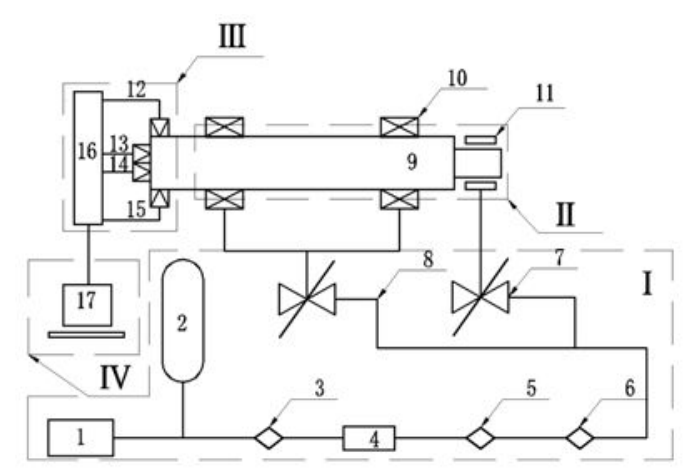

1-Air compressor; 2-Gas storage tank; 3-High temperature freeze drier; 4-Separator filter; 5-Main pipeline filter; 6-Oil removal filter; 7-Turbine valve; 8-Bearing gas supply valve; 9-Bearing rotor; 10-Gas bearing; 11-Turbine; 12, 13, 14- X, Y, Z axis laser displacement sensor; 15-Speed sensor; 16-Data acquisition device; 17-Computer

Fig. 16 Overall scheme diagram of test machine 


\subsection{Main structure of test machine}

The main structure of bearing test machine is shown in Fig 17. The gas bearing test machine is mainly composed of bearing rotor system, driving turbine, bearing seat and frame. The hemispherical diameter of the bearing testing machine is $15 \mathrm{~mm}$ and the gas film thickness is $10 \mu \mathrm{m}$. The structural parameters are shown in Table 1.

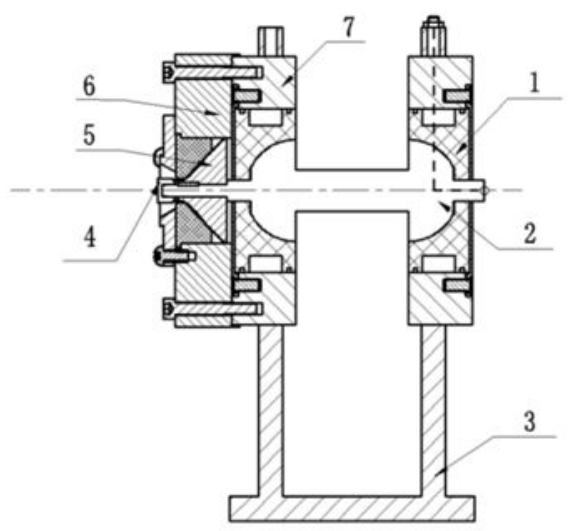

1-Gas bearing; 2-Gas bearing rotor; 3-Frame; 4-Turbine end cover; 5-Turbine; 6-Turbine cover; 7- Bearing seat

Fig. 17 Main structure of test machine

Table 1. The design parameters of gas bearings

\begin{tabular}{cc}
\hline Structure name & Parameter \\
\hline Bearing diameter $\phi_{1}(\mathrm{~mm})$ & 15 \\
Groove depth ratio $\bar{h}$ & 3.6 \\
Groove width ratio $\bar{b}$ & 0.4 \\
The number of grooves $N_{g}$ & 6 \\
Helix angle $\beta\left(^{\circ}\right)$ & 70 \\
The average gas film thickness $h_{0}(\mu \mathrm{m})$ & 10 \\
Small hole diameter $\phi_{2}(\mathrm{~mm})$ & 0.2 \\
Gas supply hole row number & 2 \\
Number of gas supply holes & 6 \\
\hline
\end{tabular}



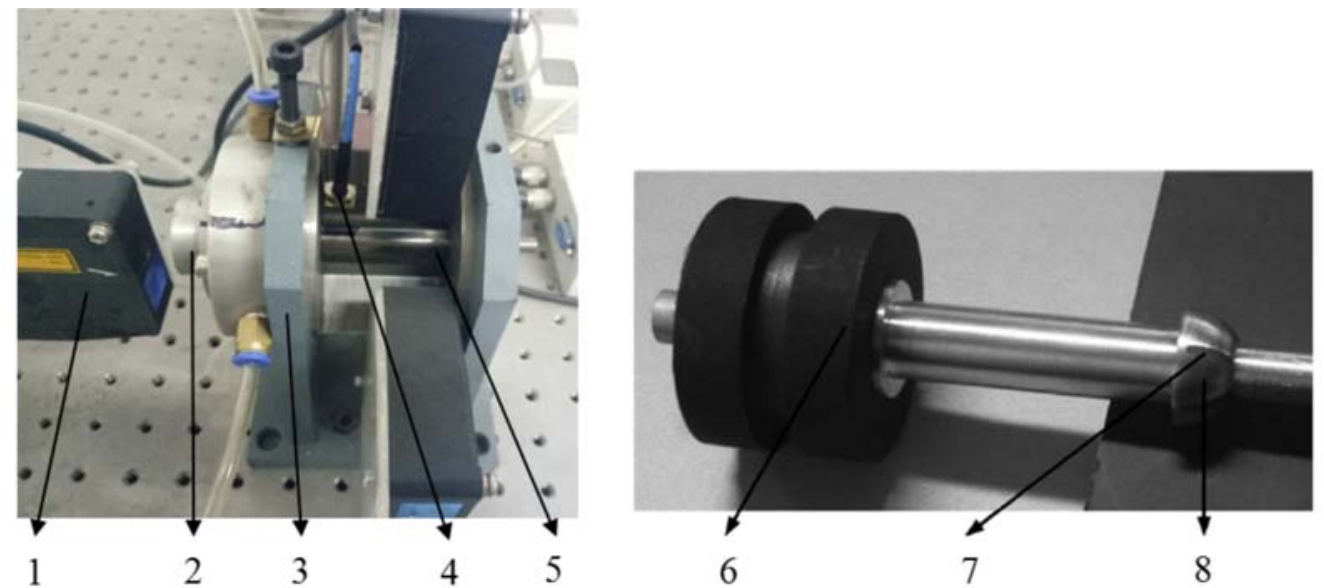

1-Laser displacement sensor; 2-Turbine; 3-Frame; 4-Speed sensor; 5-Gas bearing-rotor system; 6-Gas bearing; 7Spiral groove; 8-Rotor

Fig. 18 Bearing test machine

\subsection{Experimental test}

The bearing gas pressure of the gas bearing test bench is adjusted to $0.3 \mathrm{Mpa}$ for test. The data processing system extracts the test data of the gas film force, vibration displacement, vibration speed and rotation speed of the rotor of $10000 \mathrm{r} / \mathrm{min}, 20000 \mathrm{r} / \mathrm{min}, 30000 \mathrm{r} / \mathrm{min}, 40000 \mathrm{r} / \mathrm{min}$, $50000 \mathrm{r} / \mathrm{min}$ and $60000 \mathrm{r} / \mathrm{min}$ respectively. According to equations (3), the gas film stiffness and damping Matlab program is used to process and calculate the experimental data, and the stiffness and damping coefficient of the gas film are obtained. Finally, the stiffness and damping coefficients with an eccentricity ratio of 0.3 is extracted, and the stiffness and damping coefficient of the bearing are obtained by the average value. The relationship between the gas film stiffness damping and the rotation speed is shown in Fig 19. 


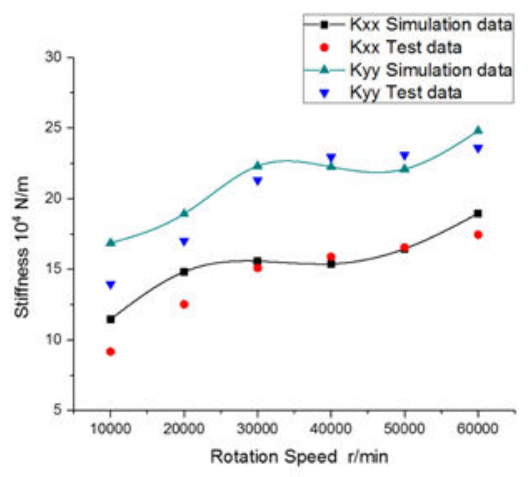

a. Direct stiffness

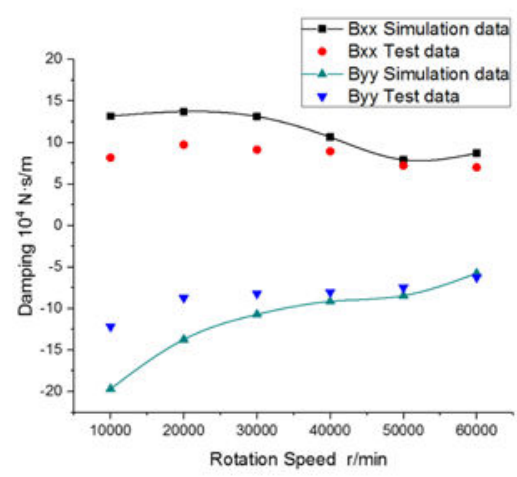

c. Direct damping

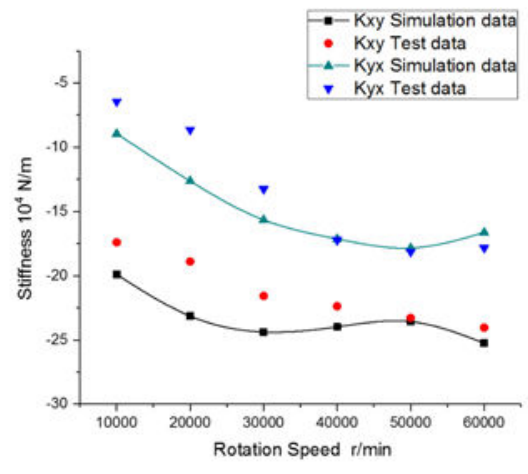

b. Cross stiffness

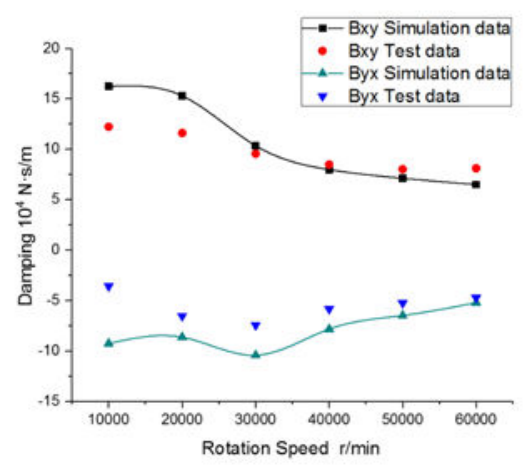

d. Cross damping

Fig. 19 Variation of rotation speed on dynamic stiffness and damping coefficients

The results demonstrate that, the comparing the results of simulation and experimental data, the change trends of the two are consistent, and there is a certain error between the simulation results and the experimental results.The assumption of some boundary conditions is more ideal when simulating simulation calculation. And the results are related to the solver model, the grid quality, the boundary conditions and the dynamic grid model, and the parameter settings. The actual rotor mass unbalance, bearing machining error, shafting assembly error and other factors have a great influence on the test results. Therefore, there are some errors in simulation and experimental data. On the whole, the test data is consistent with the simulation results. The correctness and validity of the simulation method of 6 DOF passive grid based on FLUENT software are verified.

\section{Conclusions}

1. Based on FLUENT, the dynamic pressure variation of the bearing gas film lubrication flow field was reflected in real-time using a 6-degrees of freedom (DOF) dynamic grid calculation method. This method examines the influence of the dynamic-static pressure coupling on the bearing lubrication flow field pressure distribution. The bearing capacity of the hybrid gas bearings is mainly composed of the static pressure effect from the gas supply pressure and the dynamic pressure effect generated by the journal rotation. An increase in the gas supply pressure can 
effectively enhance the static pressure effect. The reduction of gas film thickness and an increase in rotation speed can enhance the dynamic pressure effect, which in turn promotes the strengthening of the bearing capacity produced by the dynamic-static pressure coupling.

2. Different rotation speeds, gas supply pressures, gas film thicknesses and eccentricity ratio will cause pressure changes in the film lubrication flow field, which will have an impact on the operational bearing capacity. The analysis indicates that higher rotation speeds and gas supply pressures gradually enhance the dynamic-static pressure coupling effect, which significantly improves the bearing capacity. In addition, the proper reduction in the gas film thickness and an increase in the eccentricity ratio can also greatly enhance the bearing capacity. Therefore, dynamicstatic pressure coupling can complement each other to enhance the capacity and stability of the bearing.

3. For the hybrid gas bearings, variations in the structural and operating parameters can change the dynamic characteristics of the gas film. We analyzed the effect of gas film thickness, eccentricity ratio, and gas supply pressure on the dynamic characteristic coefficients and examined the mechanical mechanism of gas bearing stability. The analysis indicates that the gas film stability depends on the interaction between the gas film stiffness and damping, of which the cross-stiffness coefficient has an effect in enhancing the action of whirl. The damping coefficient is a factor that suppresses the whirl. Proper parameter selection can increase the bearing capacity, optimize the bearing's dynamic characteristics, reduce the whirl of the gas film, and provide a theoretical basis for improving the operating stability of the gas bearing.

\section{Acknowledgement}

This work is supported by National Natural Science Foundation of China (Grant no: 51475142), and Program for Innovative Research Team (in Science and Technology) in University of Henan Province (Grant no: 13IRTSTHN025).

\section{References}

Chen, Y.S., Chiu, C.C., and Cheng, Y.D. 2010. Influences of operational conditions and geometric parameters on the stiffness of aerostatic journal bearings. Precis. Eng.-J. Int. Soc. Precis. Eng. Nanotechnol. 34(4): 722-734. doi:10.1016/j.precisioneng.2010.04.001.

Jia, C.H., Pang, H.J., Ma, W.S., and Qiu, M. 2016. Dynamic stability prediction of spherical spiral groove hybrid gas bearings rotor system. J. Tribol.-Trans. ASME, 139(2): 021701-021713. doi:10.1115/1.4033453.

Jia, C.H., Pang, H.J., Ma, W.S., and Qiu, M. 2017. Analysis ofdynamic characteristics and stability prediction of gas bearings. Ind. Lubr. Tribol. 69(2): 123-130. doi:10.1108/ilt-09-2015-0134. 
Li, Q., Zhang, S., Ma, L., Xu, W.W., and Zheng, S.Y. 2017. Stiffness and damping coefficients for journal bearing using the 3D transient flow calculation. J. Mech. Sci. Technol. 31(5): 2083-2091. doi:10.1007/s12206017-0405-9.

Liu, R., and Wang, X.L. 2011. Dynamic characteristics analysis of micro air spiral grooved thrust bearing-rotor system. $6^{\text {th }}$ IEEE International Conference on Nano/Micro Engineered and Molecular Systems, Kaohsiung, Taiwan, 20-23 Feb. 2011. IEEE, Kaohsiung, Taiwan. pp. 719-723.

Lu, Z.W., and Wei, M.M. 2014. Numerical simulation and experimental study of the static performance of the aerodynamic bearings. Tribology, 34(1): 36-42. doi:10.16078/j.tribology. 2014.01.010.

Ma, W.Q., Yu, H.C., and Sun, A. 2010. Research situation of gasbearing/ rotor system. Lubr. Eng. 35(6): 121-125. doi:10.3969/ j.issn.0254-0150.2010.06.029. Miyatake, M., and Yoshimoto, S. 2010. Numerical investigation of static and dynamic characteristics of aerostatic thrust bearings with small feed holes. Tribol. Int. 43(8): 13531359. doi:10.1016/j.triboint.2010.01.002.

Nishio, U., Somaya, K., and Yoshimoto, S. 2011. Numerical calculation and experimental verification of static and dynamic characteristics of aerostatic thrust bearings with small feedholes. Tribol. Int. 44(12): 1790-1795. doi:10.1016/ j.triboint.2011.07.004.

Qi, S.M., Geng, H.P., and Yu, L. 2007. Dynamic stiffness and dynamic damping coefficients of aerodynamic bearings. J. Mech. Eng. 43(5): 91-98. doi:10.3321/j.issn:0577-6686.2007. 05.016.

Rashidi, R., Mohammadi, A.K., and Nejad, F.B. 2010. Bifurcation and nonlinear dynamic analysis of a rigid rotor supported by two-lobe noncircular gas-lubricated journal bearing system. Nonlinear Dyn. 61(4): 783-802. doi:10.1007/s11071-010-9687-5.

San Andrés, L. 2006. Hybrid flexure pivot-tilting pad gas bearings: analysis and experimental validation. J. Tribol. 128(3): 551-558. doi:10.1115/1.2194918.

Theisen, L.R., Niemann, H.H., Galeazzi, R., and Santos, I.F. 2015. Gas bearing control for safe operation in critical speed regions-experimental verification. 12th European Workshop on Advanced Control and Diagnosis, Pilsen, Czech Republic, 19-20 Nov. 2015. Institute of Physics Publishing, Pilsen, Czech Republic. pp. 012-017.

Wang, B., Sun, Y.T., and Ding, Q. 2016. Dynamic characteristics of the herringbone groove gas journal bearings: numerical simulations. Shock Vib. 2016: 1-13. doi:10.1155/2016/8743016.

Xu, F.C., Liu, Z.S., Ma, R.X., and Huang, F.L. 2014. Dynamic performance tests of bump-type gas foil journal bearing-rotor system in start-up and shut-down procedures. J. Aerosp. Power, 29(1): 216-224. doi:10.13224/j.cnki.jasp.2014.01.028.

Yu, H.C., Ma, W.Q., Wang, Z.W., and Xu, L.F. 2009. Research on static characteristics of radial aerostatic bearings based on FLUENT. Lubr. Eng. 34(12): 77-81. doi:10.3969/j.issn.0254-0150.2009.12.020.

Yu, P.L., Chen, X.D., Wang, X.L., and Jiang, W. 2015. Frequency dependent nonlinear dynamic stiffness of aerostatic bearings subjected to external perturbations. Int. J. Precis.Eng. Manuf. 16(8): 1771-1777. doi:10.1007/s12541-015-0232-9.

Zhang, G.H., and Liu, Z.S. 2011. Performance analysis of membrane restrictor hybrid journal gas bearings. Chin. J. Mech. Eng. 47(3): 73-80. doi:10.3901/JME.2011.03.073.

Zhang,W.M., Zhou, J.B., and Meng, G. 2011. Performance and stability analysis of gas-lubricated journal bearings in MEMS. Tribol. Int. 44(7-8): 887-897. doi:10.1016/j.triboint. 2011.03.004.

Zhang, Y.F., Hei, D., Lü, Y.J.,Wang, Q.D., and Müller, N. 2014. Bifurcation and chaos analysis of nonlinear rotor system with axial-grooved gas-lubricated journal bearing support. Chin. J. Mech. Eng. 27(2): 358-368. doi:10.3901/CJME.2014.02.358. 


\title{
Research on dynamic characteristics of
} gas film of spherical hybrid gas bearings based on computational fluid dynamics

\author{
Jia, Chenhui
}

Canadian Society for Mechanical Engineering

Jia C, Cui Z, Guo S, Ma W. (2019) Research on dynamic characteristics of gas film of spherical hybrid gas bearings based on computational fluid dynamics. Transactions of the Canadian Society for Mechanical Engineering, Volume 44, Issue 1, March 2020, pp. 23-37 https://doi.org/10.1139/tcsme-2018-0134

Downloaded from Cranfield Library Services E-Repository 